\title{
Produção integrada de Tambacu (Piaractus mesopotamicus Holmberg, 1887 x Colossoma macropomum Cuvier, 1818) e alface (Lactuca sativa L.) em sistema com recirculação de água
}

\author{
Monique Virães Barbosa Santos \\ Instituto Federal de Educação, Ciência e Tecnologia do Mato Grosso (IFMT) \\ (monique.viraes@gmail.com) \\ Cristian Jacques Bolner Lima \\ Instituto Federal de Educação, Ciência e Tecnologia do Mato Grosso (IFMT) \\ (cristian.lima@cas.ifmt.edu.br) \\ Otávio Miranda Verly \\ Instituto Federal de Educação, Ciência e Tecnologia do Mato Grosso (IFMT) \\ (verly.miranda@gmail.com) \\ Natália Cardoso Procópio \\ Instituto Federal de Educação, Ciência e Tecnologia do Mato Grosso (IFMT) \\ (nataliac.ardosoproc.opio@gmail.com) \\ Júlio César Passos \\ Instituto Federal de Educação, Ciência e Tecnologia do Mato Grosso (IFMT) \\ (julio.passos@gmail.com)
}

\begin{abstract}
Resumo: $\mathrm{O}$ avanço da piscicultura no mundo está levando à intensificação do descarte de efluentes no ambiente, acarretando sérios riscos à natureza. No entanto, com a aquaponia, sistema integrado de criação de peixes com produção vegetal, tais resíduos deixam de ser descartados e passam a ser reaproveitados pelos vegetais. O objetivo deste trabalho é avaliar o crescimento de alfaces (Lactuca sativa) e tambacus (Colossoma macropomum X Piaractus mesopotamicus), bem como analisar a qualidade da água, a fim de validar a integração da piscicultura intensiva e da hidroponia em sistema de recirculação fechado. A estrutura aquapônica foi composta por um tanque de 1.000 litros para a criação dos peixes, pelo sistema hidropônico Nutrient Film Thecnic (NFT) para o cultivo dos vegetais e, ainda, por um filtro biológico. Foram alojados, nos tanques de criação de peixes, 50 alevinos com peso médio de $15,34 \mathrm{~g}$ e com comprimento total médio de $9,36 \mathrm{~cm}$. Nos canais hidropônicos, foram introduzidas 25 mudas de alface. Ao final do experimento, os tambacus obtiveram 12,22 g de ganho de peso e 2,06 cm de aumento no comprimento total. No mesmo período, 22 exemplares de alfaces morreram e os três que restaram não se desenvolveram. Conclui-se que o crescimento e a sobrevivência das alfaces não foram viáveis no sistema de aquaponia estudado, ao contrário dos tambacus, que obtiveram bom desempenho zootécnico.
\end{abstract}

Palavras-chave: Aquaponia; Piscicultura; Hidroponia.

Integrated production of Tambacu (Piaractus mesopotamicus Holmberg, $1887 \mathrm{x}$ Colossoma macropomum Cuvier, 1818) and lettuce (Lactuca sativa L.) in water recirculation system

Abstract: The advancement of pisciculture in the world is leading to intensification the discard of effluents in the environment and causing serious risks to nature. However, with the aquaponics, which is the integration, such waste ceases to be discarded, and become reused by plants. The objective of this work was to evaluate the growth of lettuce (Lactuca sativa) and tambacus (Piaractus 
mesopotamicus X Colossoma macropomum), as well as to analyze the water quality in order to validate the integration of intensive fish farming and hydroponics in a closed recirculation system. The aquaponic system was composed of a tank of 1,000 liters for the creation of fish, by the hydroponic system Nutrient Film Thecnic (NFT) and by a biological filter for the cultivation of the vegetables. Fifty fingerlings with a mean weight of $15.34 \mathrm{~g}$ and length of $9.36 \mathrm{~cm}$ were housed in the fish rearing tanks, and the hydroponic channels were introduced 25 seedlings of lettuce. The tambacus gained $12.22 \mathrm{~g}$ of weight and $2.06 \mathrm{~cm}$ on total length, at the same time that 22 individuals of lettuce died and the remaining three have not developed. It is concluded that growth and survival of the lettuce were not viable in the aquaponics system studied, unlike of the tambacus that achieved good zootechnical performance.

Keywords: Aquaponics; Pisciculture; Hydroponics.

\section{INTRODUÇÃO}

Entre os sistemas de cultivo de peixes praticados em vários países, inclusive no Brasil, destaca-se o superintensivo, no qual a aplicação de tecnologias, monitoramento da qualidade da água e uso de ração de boa qualidade permitem que sejam adotadas elevadas densidades populacionais no sistema, sem prejuízo no desenvolvimento dos peixes.

Dentre os riscos proporcionados por esse sistema de cultivo, destaca-se a porção do alimento não utilizada pelos peixes e excretada como resíduo orgânico na forma de sólidos fecais. O descarte do efluente do viveiro no ambiente acarreta sérios riscos à natureza, tais como poluição, hibridação, introdução de espécies exóticas, aumento da consanguinidade, superprodução de algas e deterioração da qualidade da água e do solo (ARANA, 1999).

Esses sólidos, juntamente com os resíduos de alimento não ingeridos, são metabolizados pelas bactérias presentes na água, as quais consomem oxigênio e produzem amônia. Esta substância, inodora e incolor, pode levar os peixes à morte devido à sua grande toxicidade (AL-HAFEDH et al.,2003).

A destoxificação da amônia pode ser obtida pelo processo de nitrificação com uso de biofiltro, no qual, de acordo com Jeris e Owens (1975), a amônia é transformada em nitrito e, depois, em nitrato por ação bacteriana, sendo este último o produto final, não tóxico. O nitrato, assim como demais nutrientes, pode ser encontrado no efluente da criação de peixes, sendo que sua extração pelos vegetais hidropônicos melhora a qualidade da água antes do seu retorno aos tanques de piscicultura (QUILLERÉ et al., 1995). Esse processo ocorre após a biodecomposição 
realizada no biofiltro, no qual os minerais dissolvem-se e ionizam-se na água, sendo absorvidos pelas plantas (RAKOCY e HARGREAVES, 1993).

Além disso, sistemas de recirculação de água integrados à hidroponia proporcionam ambiente artificial, controlado, que otimiza tanto o desenvolvimento de peixes quanto de plantas cultivadas sem solo, conservando os recursos hídricos (RAKOCY e HARGREAVES, 1993) e criando um ambiente simbiótico entre peixes, bactérias e plantas (QUILLERÉ et al.,1995).

As preocupações e consequente pressão da sociedade relativas à realidade socioeconômica e ambiental exigem mudanças nos padrões de utilização dos recursos naturais. Para isso, considera-se fundamental desenvolver sistemas de produção, no Brasil, baseados em outro padrão de exploração agrícola, convergido para um modelo de desenvolvimento sustentável.

Como não há muitos estudos sobre a integração da piscicultura com espécies nativas e a hidroponia, diante das preposições anteriores objetivou-se, com este experimento, verificar o desenvolvimento e a sobrevivência do tambacu (Piaractus mesopotamicus Holmberg, 1887 X Colossoma macropomum Cuvier, 1818) e de alfaces (Lactuca sativa L.), sem o uso de fertilizantes, em sistema de recirculação da água com uso de biofiltro.

\section{METODOLOGIA}

O experimento foi realizado no Laboratório de Piscicultura do Instituto Federal de Educação, Ciência e Tecnologia do Mato Grosso (IFMT), Campus Cáceres Prof. Olegário Baldo, cujas coordenadas geográficas são $16^{\circ} 13^{\prime} 55,1^{\prime \prime}$ de latitude sul e $57^{\circ} 51^{\prime} 46,2^{\prime \prime}$ de longitude oeste, com uma altitude de $117 \mathrm{~m}$. Este trabalho ocorreu durante 28 dias, no período compreendido entre meados de março a abril de 2016.

O sistema de aquaponia foi composto por uma caixa d'água de 1.000 litros, a qual serviu como tanque para a criação dos peixes. Para o cultivo dos vegetais, utilizou-se o sistema hidropônico Nutrient Film Thecnic (NFT), instalado acima do tanque dos peixes e confeccionado em tubo de pvc $(75 \mathrm{~mm})$ perfurado com serracopo para o encaixe de copos plásticos descartáveis. Também havia uma bomba submersa, com vazão de $2.000 \mathrm{~L} / \mathrm{h}$, instalada no tanque dos peixes para 
arecirculação de água, e um tambor plástico de 50 litros, que serviu como filtro biológico.

Os peixes foram adquiridos de um produtor de alevinos de Glória D’OesteMT. Foram utilizados tambacus, que é um híbrido obtido através do cruzamento entre a fêmea de tambaqui (Colossoma macropomum) e o macho de pacu (Piaractus mesopotamicus). No tanque de cultivo de peixes, foram alojados 50 alevinos com peso médio inicial de $15,34 \mathrm{~g}( \pm 2,89)$ e comprimento total médio inicial de $9,36 \mathrm{~cm}( \pm 5,47)$. Os peixes foram alojados uma semana antes da introdução das alfaces no sistema de aquaponia, a fim de aclimatá-los à estrutura e colonizar o filtro biológico com bactérias nitrificantes. A alimentação era ofertada três vezes ao dia, às $8 \mathrm{~h}$, às $12 \mathrm{~h}$ e às $16 \mathrm{~h}$, ad libitum, com ração para peixes onívoros contendo $32 \%$ de proteína bruta (PB) e tamanho de $6 \mathrm{~mm}$.

Para o cultivo de vegetais, foram introduzidas 25 mudas de alface, obtidas no Setor de Olericultura do Campus Cáceres, semeadas cerca de 15 dias antes de colocá-las em hidroponia. As mudas utilizadas no sistema hidropônico apresentavam $4,56( \pm 0,74)$ número médio de folhas, $4,28 \mathrm{~cm}( \pm 0,78)$ altura das folhas e $9,99 \mathrm{~cm}$ $( \pm 2,05)$ de comprimento de raiz. Cada muda de alface foi acondicionada num copo plástico descartável de $50 \mathrm{~mL}$, perfurado para permitir a irrigação das raízes com o efluente do tanque dos peixes.

Através da bomba submersa alojada no tanque dos peixes, o efluente era coletado e passava pelo biofiltro com a finalidade de remover fezes e restos de ração, mas, principalmente, para transformar a amônia em nitrito e este em nitrato por meio das bactérias do ambiente. A água filtrada chegava aos vegetais por gravidade, os quais assimilavam os nutrientes dissolvidos. Após a passagem pelos vegetais, a água retornava ao tanque dos peixes também por ação da gravidade.

Semanalmente, às 10 horas, era realizado o monitoramento da qualidade físico-química da água. Os parâmetros de água analisados foram temperatura, com auxílio de termômetro, pH, oxigênio dissolvido, amônia e nitrito, estes através de testes específicos.

As medições de peso e comprimento total dos tambacus e alfaces foram realizadas no início e no final do experimento, através de balança e paquímetro, respectivamente, com a finalidade de calcular parâmetros zootécnicos e índices de produção de plantas. Além disso, semanalmente realizava-se análise visual das 
alfaces, a fim de verificar possíveis sintomas de deficiências de macro nutrientes, descritos por Pacheco et al. (2011).

Os dados coletados foram tabulados e processados no Software Microsoft Office Excel 2010, no qual foram calculadas as médias e os desvios das variáveis.

\section{RESULTADOS E DISCUSSÕES}

Os parâmetros de temperatura, $\mathrm{pH}$, oxigênio dissolvido da água e amônia encontravam-se dentro da faixa recomendada para o bem-estar de peixes e vegetais, exceto o nitrito (Tabela 1 ).

O Conselho Nacional de Meio Ambiente (CONAMA), através da Resolução 357/2005, recomenda os seguintes valores dos parâmetros de qualidade da água, de acordo com a classe 2, que classifica águas destinadas à criação natural e/ou intensiva de organismos aquáticos: temperatura da água $=28-32^{\circ} \mathrm{C} ; \mathrm{pH}=6,5-8,0$; oxigênio dissolvido $>5,0 \mathrm{mg} / \mathrm{L}$; nitrogênio amoniacal total $\leq 2,0 \mathrm{mg} / \mathrm{L}$ de $\mathrm{N}$.

Tabela 1. Valores médios dos parâmetros de qualidade de água no sistema de aquaponia.

\begin{tabular}{llll}
\hline Parâmetros & Valores médios & Valor mínimo & Valor máximo \\
\hline Temperatura $\left({ }^{\circ} \mathrm{C}\right)$ & $27,3 \pm 0,22$ & 27 & 27,5 \\
pH & $7,5 \pm 0,33$ & 7 & 8 \\
Oxigênio dissolvido $(\mathrm{mg} / \mathrm{L})$ & $11 \pm 0,0$ & 11 & 11 \\
Amônia tóxica $(\mathrm{mg} / \mathrm{L})$ & $0,0113 \pm 0,01$ & 0,002 & 0,028 \\
Nitrito $(\mathrm{mg} / \mathrm{L})$ & $2,8 \pm 0,0$ & 2,8 & 2,8 \\
\hline
\end{tabular}

De acordo com Carneiro et al. (2015), as bactérias nitrificantes são predominantemente aeróbicas e têm o pH ótimo no intervalo entre 7,0 e 8,0. Por outro lado, a maioria das plantas cultivadas em hidroponia cresce melhor em $\mathrm{pH}$ entre 5,5 e 6,5. Já para a maioria das espécies de peixes de água doce de interesse econômico e que podem ser utilizadas em um sistema aquapônico, o pH ideal encontra-se entre 7,5 e 9,0. Contudo, Rakocy et al. (2006) consideram que a manutenção do $\mathrm{pH}$ próximo a 7,0 é a opção mais adequada para atender a todos os componentes biológicos presentes em um sistema aquapônico.

Durante as análises semanais, observou-se que o nitrito estava muito acima do limite indicado para produção de peixes $(0,5 \mathrm{mg} / \mathrm{L})$, e também pode ter afetado 0 desenvolvimento das alfaces, já que ele não é a forma de nitrogênio assimilável 
(FAQUIN, 2005). Portanto, havia quantidade insuficiente das formas de nitrogênio assimiláveis - amônio e nitrato. Isso sugere que o filtro não foi colonizado pelas bactérias Nitrobacter, que fazem a nitratação (processo em que ocorre a oxidação do nitrito a nitrato), apenas pelas Nitrosomonas e Nitrosococcus, que fazem a nitrozação (oxidam amônia/amônio a nitrito).

Um fator que deve ter contribuído para não haver bactérias do gênero Nitrobacter é que o filtro era novo, tendo apenas sete dias quando o sistema aquapônico foi iniciado e, segundo Francis-Floyd et al. (2009), geralmente são necessários de 20 a 30 dias para um sistema aquapônico apresentar seu ciclo de nitrificação em equilíbrio.

Em relação aos tambacus, seu crescimento e sua sobrevivência foram viáveis no sistema de aquaponia estudado, observando-se ganho de peso (+ 12,22 g), de comprimento total $(+2,06 \mathrm{~cm})$ e baixa taxa de mortalidade $(10 \%)$ (Tabela 2$)$.

Tabela 2. Parâmetros zootécnicos dos alevinos de tambacus em sistema de aquaponia.

\begin{tabular}{lccc}
\hline Parâmetros & Início & Fim & Incremento \\
\hline Peso médio $(\mathrm{g})$ & $15,34 \pm 2,89$ & $27,56 \pm 5,22$ & $+12,22$ \\
Ganho de peso diário - GPd (g/dia) & - & 0,44 & \\
Biomassa $(\mathrm{g})$ & 767 & 1.240 & +473 \\
Comprimento total $(\mathrm{cm})$ & $9,36 \pm 5,47$ & $11,42 \pm 0,70$ & $+2,06$ \\
Sobrevivência $(\%)$ & - & 90 & -10 \\
\hline
\end{tabular}

Os resultados obtidos neste trabalho com as alfaces indicam que a produção foi insatisfatória devido à alta mortalidade (88\%), à redução do crescimento do sistema radicular $(-1,90)$ e à perda de folhas $(-1,23)$ (Tabela 3$)$.

Tabela 3. Valores médios obtidos com os exemplares de alface em sistema de aquaponia.

\begin{tabular}{llll}
\hline Parâmetros & \multicolumn{1}{c}{ Início } & \multicolumn{1}{c}{ Fim } & Incremento \\
\hline № de folhas & $4,56 \pm 0,74$ & $3,33 \pm 0,44$ & $-1,23$ \\
Comprimento do sistema radicular $(\mathrm{cm})$ & $9,99 \pm 2,05$ & $8,09 \pm 2,16$ & $-1,90$ \\
Comprimento do sistema foliar $(\mathrm{cm})$ & $4,28 \pm 0,78$ & $8,1 \pm 0,86$ & $+3,82$ \\
Sobrevivência (\%) & - & 12 & \\
\hline
\end{tabular}

Durante o período experimental, observaram-se sintomas de deficiência de alguns nutrientes, tais como alta mortalidade e alfaces apresentando número reduzido de folhas, estando, muitas delas, murchas ou mortas. Esses sintomas podem ser causados pela deficiência de nitrogênio, fósforo, potássio, cálcio e 
magnésio, conforme descrito por Pacheco et al. (2011). Portanto, infere-se que não havia adequadamente nutrientes na água.

Cortez (1999) cultivou alface hidropônica associada à criação de matrinxãs (Brycon cephalus) e afirmou que a produção e a qualidade deste vegetal foram semelhantes aos valores obtidos na hidroponia convencional. Relatou, também, que o sistema tornou-se viável desde que se adotou a complementação mineral, principalmente de potássio e magnésio, para o pleno desenvolvimento da planta.

No entanto, Cortez et al. (2000), testando duas soluções nutritivas, observaram peso médio de $388 \mathrm{~g}$ para o cultivar Verônica e $441 \mathrm{~g}$ para o cultivar Tainá em um período de 52 dias. Já Parker et al. (1990), sem a adoção de complementação mineral, obtiveram plantas com peso médio de $50 \mathrm{~g}$, e Rakocy et al. (1989) observaram valores médios variando de 98 a $131 \mathrm{~g}$ em um período de 42 dias, sendo também insatisfatório comercialmente.

Castellani et al. (2009) inferiram que o sistema integrado do berçário secundário do camarão-da-amazônia com o cultivo hidropônico de hortaliças apresentou aplicabilidade positiva, obtendo-se plantas com maiores fitomassas quando suplementadas com solução nutritiva por meio de pulverização semanal e gotejamento.

\section{CONCLUSÕES}

O crescimento e a sobrevivência dos tambacus foram viáveis no sistema de aquaponia estudado. Entretanto, não foram obtidos resultados satisfatórios em relação à produção de alface. Isso pode ter ocorrido devido à deficiência de nitrogênio em suas formas assimiláveis: amônio e nitrato.

No entanto, fazem-se necessários mais estudos sobre este tema, tendo em vista que a produção de alimentos ocorre de forma integrada com economia de água e aproveitamento do efluente da produção de peixes para nutrição de vegetais.

\section{AGRADECIMENTOS}


À Pró-Reitoria de Pesquisa e Inovação do Instituto Federal de Mato Grosso (IFMT), pela concessão de auxílio financeiro, o qual possibilitou a concretização desta pesquisa. Ao CNPq e à FAPEMAT, pela concessão de bolsas de iniciação científica aos discentes do Laboratório de Piscicultura. Ao IFMT, Campus Cáceres, pelo apoio ao desenvolvimento deste trabalho.

\section{REFERÊNCIAS}

AL-HAFEDH, Y. S.; ALAM, A.; ALAM, A. M. Performance of plastic biofilter media with different configuration in a water recirculation system for the culture of Nile tilápia (Oreochromis niloticus). Aquacultural Engineering, v.29, n.3-4, p.139-154, 2003.

ARANA, L. V. Aqüicultura e desenvolvimento sustentável: subsídios para a formulação de políticas de desenvolvimento da aqüicultura brasileira. Ed UFSC - Florianópolis, 1999. $310 \mathrm{p}$.

CARNEIRO, P. C. F.; et al. Aquaponia: produção sustentável de peixes e vegetais. In: TavaresDias, M.; Mariano, W. S. (Org.). Aquicultura no Brasil: novas perspectivas. São Carlos, Editora Pedro \& João, 2015.

CASTELLANI, D.; CAMARGO, A. F. M.; ABIMORAD, E. G. Aquaponia: aproveitamento do efluente do berçário secundário do Camarão-da-Amazônia (Macrobrachium amazonicum) para produção de alface (Lactuca sativa) e agrião (Rorippa nasturtium aquaticum) hidropônicos. Bioikos, Campinas, 23(2):67-75, 2009.

CONAMA - Conselho Nacional do Meio Ambiente. Resolução no 357/2005. Estabelece a classificação das águas doces, salobras e salinas no Território Nacional. Brasília, SEMA, 2005.

CORTEZ, G. E. P. Cultivo de alface por hidroponia associado à criação de peixes. Tese Faculdade de Ciências Agrárias e Veterinárias, Universidade Estadual Paulista. 1999

CORTEZ, G. E. P.; ARAUJO, J. A. C.; BERLLINGIERI, P. A. Cultivo de alface em hidroponia associado à criação de peixes. I. Qualidade da água. Anais do Congresso Brasileiro de Olericultura, 2000, São Pedro. Brasília: Horticultura Brasileira. v.18, p.192-3, 2000.

FAQUIN, V. Nutrição Mineral de Plantas. Monografia (Curso de Pós graduação Lato Sensu em Solos e Meio Ambiente). Lavras, UFLA, 2005.

FRANCIS-FLOYD, R. et al. Ammonia in aquatic systems. Univ. Florida Dept. Fisheries Aquatic Sci., Florida Coop. Ext. Serv. FA-16. 2009.

JERIS, J.; OWENS, R. W. Pilot-scale, high rate biological denitrification. Journal Water Pollut Control Federation, n.47, n.8, p.2943-2957, 1975.

PACHECO SILVA ML; RODRIGUES MA; BIANCO MS; CECÍLIO FILHO AB; GAION LA. 2011. Caracterização de sintomas visuais de deficiências de macronutrientes em alface. Horticultura Brasileira, v.29, n. 2 (Suplemento - CD ROM), 2011. 
PARKER, D.; ANOUT, A.; DICKENSON, G. Experimental results integrated fish/plant production system. Tucson (TX): University of Arizona. 1990.

QUILLERÉ, L.; ROUX, L.; MARIE, D. An artificial productive ecosystem based on a fish/ bacteria/ plant association. 2. Performance. Agriculture, Ecosystems and Enviroment, v.53, p.19-30, 1995.

RAKOCY, J. E.; HARGREAVES, J. A.; BAILEY, D. S. Effects of hydroponics vegetable production on water quality in a closed recirculating system. Journal World Aquaculture Society, v. 20, n. 3, p. 64A, 1989.

RAKOCY, J.E.; HARGREAVES, J.A. Integration of vegetable hydroponics with fish cuture: a review. Techniques for Modern Aquaculture, p.112-136, 1993.

RAKOCY, J. E.; LOSORDO, T. M.; MASSER. M. P. Recirculating aquaculture tank production systems: Auqaponics - Integrating fish and plant culture. Southern Reg. Aquaculture Center Publications, v. 454, 2006. 